\title{
Overall and income specific effect on prevalence of overweight and obesity of $20 \%$ sugar sweetened drink tax in UK: econometric and comparative risk assessment modelling study
}

\author{
(c) $\underset{1}{(1)(8)}$ OPEN ACCESS
}

\author{
Adam D M Briggs academic clinical fellow ${ }^{1}$, Oliver T Mytton academic clinical fellow ${ }^{12}$, Ariane \\ Kehlbacher lecturer ${ }^{3}$, Richard Tiffin director ${ }^{3}$, Mike Rayner director ${ }^{1}$, Peter Scarborough senior \\ researcher $^{1}$
}

${ }^{1}$ British Heart Foundation Health Promotion Research Group, Nuffield Department of Population Health, University of Oxford, Oxford OX3 7LF, UK; ${ }^{2}$ UK Health Forum, Victoria House, Southampton Row, London WC1B 4AD, UK; ${ }^{3}$ Centre for Food Security, University of Reading, PO Box 237 , Whiteknights, Reading RG6 6AR, UK

\begin{abstract}
Objective To model the overall and income specific effect of a $20 \%$ tax on sugar sweetened drinks on the prevalence of overweight and obesity in the UK.

Design Econometric and comparative risk assessment modelling study. Setting United Kingdom.

Population Adults aged 16 and over.

Intervention A $20 \%$ tax on sugar sweetened drinks.

Main outcome measures The primary outcomes were the overall and income specific changes in the number and percentage of overweight (body mass index $\geq 25$ ) and obese $(\geq 30)$ adults in the UK following the implementation of the tax. Secondary outcomes were the effect by age group (16-29, 30-49, and $\geq 50$ years) and by UK constituent country. The revenue generated from the tax and the income specific changes in weekly expenditure on drinks were also estimated.

Results A 20\% tax on sugar sweetened drinks was estimated to reduce the number of obese adults in the UK by $1.3 \%$ (95\% credible interval $0.8 \%$ to $1.7 \%$ ) or 180000 (110 000 to 247000 ) people and the number who are overweight by $0.9 \%$ ( $0.6 \%$ to $1.1 \%$ ) or 285000 (201 000 to 364 000) people. The predicted reductions in prevalence of obesity for income thirds 1 (lowest income), 2, and 3 (highest income) were $1.3 \%$ (0.3\% to $2.0 \%), 0.9 \%(0.1 \%$ to $1.6 \%)$, and $2.1 \%(1.3 \%$ to $2.9 \%)$. The effect on obesity declined with age. Predicted annual revenue was $£ 276 \mathrm{~m}(£ 272 \mathrm{~m}$ to $£ 279 \mathrm{~m}$ ), with estimated increases in total expenditure on drinks for income thirds 1,2 , and 3 of $2.1 \%(1.4 \%$ to $3.0 \%), 1.7 \%$ (1.2\% to $2.2 \%$ ), and $0.8 \%(0.4 \%$ to $1.2 \%)$.
\end{abstract}

Conclusions A $20 \%$ tax on sugar sweetened drinks would lead to a reduction in the prevalence of obesity in the UK of 1.3\% (around 180 000 people). The greatest effects may occur in young people, with no significant differences between income groups. Both effects warrant further exploration. Taxation of sugar sweetened drinks is a promising population measure to target population obesity, particularly among younger adults.

\section{Introduction}

The growing evidence of the negative health effects of sugar sweetened drinks has led to calls for action to limit consumption. ${ }^{12}$ Several options exist, including controls on the marketing of sugar sweetened drinks, limits on portion sizes, and taxation. ${ }^{3}$ In the United Kingdom, the sale of sugar sweetened drinks in schools and their advertisement during children's television is banned. Raising the price through taxation, as happens with alcohol and tobacco, has recently been recommended as an option in the UK. ${ }^{14}$

A tax on sugar sweetened drinks may be an effective measure to improve health for several reasons. Firstly, good evidence shows that regular consumption of sugar sweetened drinks is associated with ill health—principally, adverse weight gain, type 2 diabetes, cardiovascular disease, and dental caries. ${ }^{5-10}$ Although much of the evidence comes from prospective cohort studies, the associations with weight gain are also supported by clinical trial data. ${ }^{5}$ Moreover, this evidence is complemented by laboratory studies that elucidate the mechanisms by which sugar sweetened drinks are likely to damage cardio-metabolic 
health. ${ }^{11}$ Secondly, as sugar sweetened drinks are weak appetite suppressants, a reduction in their consumption is likely to lead to a reduction in calorie intake, with people being unlikely to seek alternative sources of calories. ${ }^{11}{ }^{12}$ Thirdly, sugar sweetened drinks are non-necessities and contain no beneficial nutrients, so direct harm from reducing consumption will not occur. Fourthly, whereas taxes on unhealthy foods may be problematic because of concern about unintended substitution effects (for example, a tax on foods high in saturated fat may lead to a shift towards salty foods),${ }^{13}$ the potential substitutes for sugar sweetened drinks (diet drinks, fruit juice, milk, water) are probably less harmful for health. Finally, from a legislative perspective, sugar sweetened drinks can be clearly defined.

In January 2013 the non-governmental organisation Sustain, supported by 61 health organisations, called for a 20 pence per litre excise duty on sugar sweetened drinks. ${ }^{4}$ In February, the Academy of Medical Royal Colleges called for a $20 \%$ tax on sugar sweetened drinks as part of its enquiry into clinical and public health solutions to the obesity epidemic. ${ }^{1}$ Although the UK government has indicated a preference for voluntary approaches to the control of obesity, it has not ruled out fiscal measures. ${ }^{14}$ Clearly, the idea of a sugar sweetened drink tax is gaining traction in the UK, but its effect on health remains uncertain. Although sales taxes on soft drinks in Ireland and France have both been associated with a reduction in consumption, the health effects have not been studied. ${ }^{15}{ }^{16}$ No significant effect on obesity of US state sales taxes has been found, although the level of taxation there has probably been too low to affect health. ${ }^{13}{ }^{17}$ The modelled estimates of the health effect of a $20 \%$ sugar sweetened drink tax in the United States vary, but such a tax has been predicted to reduce obesity by up to three percentage points. ${ }^{13}{ }^{18}$ The effect of a sugar sweetened drink tax in the UK has not, until now, been formally estimated. The markedly different levels of consumption of sugar sweetened drinks in the United States and the UK (735 $\mathrm{kJ} /$ person/day in the US compared with $209 \mathrm{~kJ}$ in the UK) suggest that a tax may have a lesser effect in the UK. ${ }^{12} 19$

One concern about sugar sweetened drink taxation (as with any indirect taxation) is that it would be regressive in its financial effect, disproportionately affecting poorer members of society, although other people have suggested that the tax may be progressive in terms of health outcomes. ${ }^{12}$ Modelling studies have yet to capture these income specific health effects by using income specific estimates of the effect of price rises. We set out formally to estimate the effect of a $20 \%$ tax on sugar sweetened drinks on obesity in the UK. We also sought to understand the health effect on different income groups.

\section{Methods}

We used household survey data to estimate the effect of a $20 \%$ tax on purchases and consumption of sugar sweetened drinks. We used the estimates generated to derive the change in energy intake, which we then used to model the effect on average body weight and prevalence of obesity in the UK (fig $1 \Downarrow$ ). We chose to model the effects on body weight because good evidence (from both trials and epidemiological studies) links regular consumption of sugar sweetened drinks to weight gain. ${ }^{8} 1012$ Moreover, data from longitudinal studies support the idea that changes in the price of sugar sweetened drinks are linked to changes in body weight. ${ }^{20}$ Other groups have used this form of modelling to estimate the effects of a sugar sweetened drink tax on obesity. ${ }^{182122}$

\section{Data—price and purchasing}

Data on prices and purchasing of drinks and foods came from the Living Costs and Food Survey, 2010. ${ }^{23}$ This is a representative sample of food and drink purchasing in the UK and uses two week food expenditure diaries. For the 2010 survey, 5263 households (12 196 people) in the UK completed the survey on total household food purchases. This was used to estimate average expenditure on sugar sweetened drinks and other drinks in 2010 for the whole population and by income group. ${ }^{24}$ Quantity purchased is also reported in the survey and, using a quantity index, the price paid can thus be derived. The survey divides purchases into 256 food and drink categories. For the purposes of the modelling, we grouped 22 drink categories and 14 milk categories into 12 main drink categories (see supplementary table A1). For the purpose of this work, we defined sugar sweetened drinks as soft drinks with added sugar. This comprised two categories from the Living Costs and Food Survey: "soft drinks, concentrated, not low calorie," which we term sugar sweetened drinks (concentrated), and "soft drinks, not concentrated, not low calorie," which we term sugar sweetened drinks (non-concentrated). The second group comprises carbonated beverages with added sugar, energy drinks, and fruit drinks with added sugar.

\section{Data-drink consumption}

Drink consumption data came from the National Diet and Nutrition Survey (2008-10), a representative survey of UK diets. ${ }^{25}$ We chose this in preference to the Living Costs and Food Survey, in which data are collected at the household level, which would have precluded our making estimates of consumption by age. The National Diet and Nutrition Survey collects data at an individual level, allowing estimates of consumption by age. It also reports consumption, in contrast to the Living Costs and Food Survey, which reports purchases. Over the period 2008-10, 2126 people completed a four day food and drink diary for the National Diet and Nutrition Survey. We matched drink categories from the Living Costs and Food Survey to those in the National Diet and Nutrition Survey (supplementary table A1). We derived overall drink consumption and consumption by thirds of equivalised (adjusted for household size and composition) income. We broke these estimates down by age (16-29, 30-49, and $\geq 50$ years).

\section{Data-body mass index and population}

To estimate the prevalence of overweight and obesity, we used the Health Survey for England, 2010, and the Scottish Health Survey, 2010. ${ }^{26}{ }^{27}$ These surveys involve objective, not self reported, measurement in large samples so that reliable estimates of the change in prevalence in different sex, age, and income subgroups could be made. We did not use the Welsh Health Survey, because it records self reported body mass index, which may underestimate true body mass index. ${ }^{28}$ We also did not use the Health Survey for Northern Ireland, because it was too small to allow us to estimate the prevalence of obesity and overweight by subgroup accurately.

We used the Health Survey for England to estimate the prevalence of overweight and obesity for Northern Ireland and Wales. The obesity prevalence reported in their respective health surveys ( $22 \%$ and $23 \%$, respectively) was closer to that observed in the Health Survey for England (26\%) than the Scottish Health Survey (28\%). ${ }^{29}{ }^{30} \mathrm{We}$ made weighted estimates of prevalence for each sex, age group, and third of equivalised income.

Estimates of the population in England, Scotland, Wales, and Northern Ireland came from the 2011 census. ${ }^{31-33}$ We combined 
these with the overweight and obesity prevalence estimates to estimate the total number of people who were overweight or obese in the four countries.

\section{Modelling step 1-effect of tax rises on drink purchases}

To simulate the effect of a tax induced price rise, we estimated price elasticities. These measure the change in quantity demanded (purchased) if the price of the product itself changes (own price elasticity) or the price of another product changes (cross price elasticity). For example, an own price elasticity of -0.9 for sugar sweetened drinks indicates that a $10 \%$ increase in the price results in a $9 \%$ lower consumption of such drinks, whereas a cross price elasticity of 0.2 between sugar sweetened drinks and milk indicates that a $10 \%$ higher price of sugar sweetened drinks leads to milk consumption being higher by $2 \%$, implying that milk is a substitute for sugar sweetened drinks.

We estimated elasticities by applying a Bayesian approach to estimate an almost ideal demand system. ${ }^{34}$ This approach ensures that the substitution patterns estimated are consistent across the different food and drink groups in the model: an increase in expenditure in one good must be matched by an appropriate reduction in expenditure on another good. We also used a modified approach to allow for the possibility that within the two week survey period of the Living Costs and Food Survey, observed purchases may differ from actual demand as stocks are either built up or run down, by treating quantity demanded as a latent variable. ${ }^{35}$ Model estimation was carried out with a Markov Chain Monte Carlo algorithm, during which latent quantities were estimated by using data augmentation. ${ }^{36}$

We aggregated the Living Costs and Food Survey drinks groups into groups as set out in figure $2 \Downarrow$ for the purposes of simulating the effects of a sugar sweetened drink tax. However, estimating a single demand system for these groups was not possible. We therefore adopted the hierarchical approach depicted in figure $2 \Downarrow$ and estimated five demand systems. The elasticities that result from this estimation are conditional and assume that the change in quantity resulting from a change in price takes place with expenditure on all of the goods in the given demand system remaining constant. To relax this assumption, we calculated unconditional elasticities. ${ }^{37}$ Unconditional elasticities allow expenditure on a group to change in response to a price change within that group. They allow, for example, an increase in expenditure on sugar sweetened drinks in response to a rise in their price that is offset by reducing expenditure on another food or drinks group.

We estimated price elasticities for the whole UK population and for the thirds of income. We then used the own price and cross price elasticity estimates to predict the percentage change in purchasing of the 12 different drink categories as a result of a $20 \%$ increase in price of sugar sweetened drinks. When modelling the health effects, we explicitly modelled these only on the basis of changes in drink consumption. This is in keeping with past work that has assumed that substitution with foods arising from a sugar sweetened drink tax is negligible. ${ }^{5918}$ Consistent with this assumption, the substitution effects we observed with respect to food were non-significant.

\section{Modelling step 2-effect of changes in drink purchases on energy intake}

We assumed the estimated percentage change in drinks purchased (derived in step 1 from Living Costs and Food Survey data) to be the same as the percentage change in consumption.
We therefore applied the estimated percentage changes in purchases to the National Diet and Nutrition Survey dataset to estimate the change in consumption of each type of drink (see supplementary table A1). We used the change in volume of drinks consumed to estimate the change in the energy intake, using measures of the average calorie density of beverages, as reported in the National Diet and Nutrition Survey. We summed the changes for each beverage to give an estimate of the net change in energy intake. We estimated income specific percentage changes by applying income specific percentage changes in consumption to income and age specific estimates of baseline consumption for the three age groups (16-29, 30-49, and $\geq 50$ years). For estimates of overall age specific changes, we applied overall percentage changes to age specific baseline consumption for the three age groups.

\section{Modelling step 3-effect of changes in energy intake on body mass index}

We modelled the change in the proportion of people who are overweight or obese by using a comparative risk assessment model known as PRIME. The PRIME model has previously been used to model the effects of dietary changes on mortality due to chronic disease in the UK setting. ${ }^{38-41}$ A detailed description of the PRIME model is available in the supplementary data of an open access article. ${ }^{42}$

The relevant section of the PRIME model used here is concerned with changes in body weight as a result of changes in total energy intake. It uses equations derived by Christiansen and Garby based on the second law of thermodynamics (concerning energy conservation). ${ }^{43}$ The equations for men and women predict a new "steady state" body weight allowing for changes in basal metabolic rate and fat distribution as weight changes. The estimates for change in body weight produced by this method are similar to those derived using Hall and Jordan's dynamic model, ${ }^{44}{ }^{45}$ which others have used to estimate the effect of a sugar sweetened drink tax on obesity. ${ }^{18}$

The PRIME model estimates the change in the distribution of body mass index for each age, sex, and third of income as a result of the change in the mean energy intake on the basis of the assumption that body mass index in the population follows a log-normal distribution and that the variance of body mass index in the population is unaffected by the change in energy intake. In our model, we also assumed that physical activity levels would not change. We used the population estimates to estimate the absolute change in the number of people who are overweight or obese.

\section{Country and income third specific estimates}

For the country specific estimates, we used age specific estimates of the change in energy intake as well as age, sex, and country specific baseline body mass index data from the appropriate health survey. For income third specific estimates, we used income third and age specific estimates of change in energy intake, as well as income, age, sex, and country specific baseline body mass index data from the appropriate health survey. Estimates of the age and sex distribution of the population in each income third by country were based on the distribution found in the Health Survey for England (for England, Wales, and Northern Ireland) and the Scottish Health Survey (for Scotland). 


\section{Estimating tax revenue and changes in expenditure}

We estimated the new expenditure on drinks by applying estimates of the percentage change in purchases (derived in step 1) to expenditure data from the Living Costs and Food Survey (with a $20 \%$ increase in the price of sugar sweetened drinks). From this, we estimated the change in expenditure on all drinks and the mean amount of tax paid per person per week. We then estimated the total additional tax revenue by multiplying the mean amount of tax paid per person by the total population in the UK aged 16 years and over. We also made estimates of change in expenditure for each third of income.

\section{Scenarios and $95 \%$ credible intervals}

The primary scenario modelled was a $20 \%$ tax. We re-ran the model for the key results assuming a $10 \%$ tax. The uncertainty surounding price elasticity estimates is illustrated by the $95 \%$ credible intervals. For estimates of the change in calorie intake, expenditure, and revenue generated, we calculated the $95 \%$ credible intervals by using 12000 iterations of a Markov Chain Monte Carlo analysis (with a burn-in period of 2000).

\section{Results \\ Consumption of sugar sweetened drinks}

According to the National Diet and Nutrition Survey, the mean volume of sugar sweetened drinks consumed is $123 \mathrm{~mL}$ per person per day. This equates to a mean energy intake of 206 $\mathrm{kJ} /$ person/day, but marked variation by age exists (table $1 \Downarrow$ ). People aged 16-29 years consume an average of 452

$\mathrm{kJ} /$ person/day from sugar sweetened drinks, and those aged 50 years and over consume an average of $96 \mathrm{~kJ} /$ person/day. Table $2 \Downarrow$ shows overall values for consumption of sugar sweetened drinks by income. Sugar sweetened drink consumption seems to have a U-shaped relation with income. A trend for greater sugar sweetened drinks consumption with increasing income exists for men, and a trend for decreasing consumption with increasing income exists for women (data not shown). Diet drinks show a trend for increasing consumption with increasing income.

\section{Elasticity estimates}

Table $3 \Downarrow$ shows selected own price and cross price elasticity estimates. Overall, the estimated own price elasticity for sugar sweetened drinks is -0.92 for concentrated drinks and -0.81 for non-concentrated drinks. The drink category that shows a relatively large substitution effect (cross price value $>0.10$; that is, a $2 \%$ or greater increase in consumption for a $20 \%$ price rise) for price rises of concentrated sugar sweetened drinks is concentrated diet soft drinks. For non-concentrated sugar sweetened drinks, relatively large substitution effects (cross price value $>0.10$ ) occur for non-concentrated diet soft drinks, concentrated sugar sweetened drinks, milk, fruit juice, and tea and coffee (table $3 \Downarrow$ ). The own price estimates for income third 1 (lowest income) are -1.03 for concentrated and -0.79 for non-concentrated; for third 2 they are -0.83 and -0.80 , and for third 3 they are -0.91 and -0.85 . The substitution patterns for each income third with respect to which drinks are substituted are similar to the overall effect, although a trend exists towards larger substitution effects in income third 1 (lowest income) (see supplementary tables A2-A4).

\section{Change in consumption results}

Table $4 \Downarrow$ shows changes in consumption of the different drinks as a result of the tax. The $20 \%$ tax is predicted to reduce consumption of concentrated sugar sweetened drinks by $15 \%$ and non-concentrated sugar sweetened drinks by $16 \%$. Compensatory increases in consumption of other drinks are particularly pronounced for diet drinks, tea and coffee, milk, and fruit juice. The pattern is broadly similar across the three income thirds. A trend exists for greater changes in consumption of sugar sweetened drinks (non-concentrated) and water as income rises and, conversely, greater changes in consumption of diet soft drinks (non-concentrated) and milk as income falls. The lowest income group also shows a greater tendency to substitute sugar sweetened drinks with fruit juice and concentrated diet soft drinks.

\section{Change in energy intake}

Table $5 \Downarrow$ shows predicted changes in energy intake. The mean reduction in energy intake from the tax is 16.7 (95\% credible interval 11.3 to 21.7 ) $\mathrm{kJ} /$ person/day. However, marked variation by age can be seen (table $5 \Downarrow$ ). People aged $16-29$ years are predicted to reduce their net energy intake by 56.3 (47.9 to 64.4) $\mathrm{kJ} /$ person/day, and those aged 50 and over are predicted to see a small (but not significant) increase of 1.7 (-2.2 to 5.9) $\mathrm{kJ} /$ person/day. People in the highest income third are predicted to have greater reductions in energy intake, although the $95 \%$ credible intervals overlap for all three income thirds. The smaller reductions in energy intake for the two lowest income thirds compared with the highest third are primarily due to a greater substitution with high fat milk (table $4 \Downarrow$ ).

\section{Effect on overweight and obesity}

Table $6 \Downarrow$ shows the overall effect of the tax on obesity. The tax is predicted to reduce the number of people in the UK who are obese by $1.3 \%$ ( $0.8 \%$ to $1.7 \%$ ) or 180000 (110 000 to 247000 ) people and the number who are overweight or obese by $0.9 \%$ (0.6\% to $1.1 \%$ ) or 285000 (201000 to 364000$)$ people. The percentage changes are similar across the four countries. The predicted reduction in prevalence of obesity in income third 3 (highest income) is $2.1 \%$ (1.3\% to $2.9 \%)$; this is greater than the reductions in income third 2 of $0.9 \%(0.1 \%$ to $1.6 \%)$ and income third 1 (lowest income) of $1.3 \%$ ( $0.3 \%$ to $2.0 \%$ ), but the credible intervals overlap (table $7 \Downarrow$ ). The effects of the taxation on obesity decline with age (tables $7 \Downarrow$ ). For the oldest age group, a suggestion of a small non-significant increase in the prevalence of overweight and obesity is apparent. The estimated reduction in mean population body mass index is 0.07 ( 0.05 to 0.09 ), with the same patterning by income and age as the predicted changes to prevalence of obesity (table $8 \Downarrow$ ).

\section{Tax revenue and expenditure}

The $20 \%$ tax is estimated to generate $£ 276 \mathrm{~m}$ ( $£ 272 \mathrm{~m}$ to $£ 279 \mathrm{~m}$ ) annually. Average weekly expenditure on sugar sweetened drinks is $61.1 \mathrm{p}$ per person before the tax and increases to $61.7 \mathrm{p}$ (61.0p to $62.5 \mathrm{p}$ ) after taxation (a $1.1 \%(-0.2 \%$ to $2.4 \%)$ increase). The net increase in expenditure on all drinks is $8.4 \mathrm{p}$ (6.8p to 10.2p) per person per week. The highest increase in expenditure on all drinks is in income third $1(9.4 \mathrm{p}(6.2 \mathrm{p}$ to $13.4 \mathrm{p})$ per person per week increase; a $2.1 \%$ (1.4\% to $3.0 \%)$ increase) compared with increases of $9.1 \mathrm{p}(6.6 \mathrm{p}$ to $11.9 \mathrm{p} ; 1.7 \%$, $1.2 \%$ to $2.2 \%$ ) in income third 2 and $6.0 \mathrm{p}$ (3.2p to $8.8 \mathrm{p} ; 0.8 \%$, $0.4 \%$ to $1.2 \%$ ) in income third 3 . 


\section{Effects of a $10 \%$ tax}

Our model predicts that a $10 \%$ tax on sugar sweetened drinks will have approximately half the effect of a $20 \%$ tax, with 89 400 (55 300 to 124500 ) fewer obese people in the UK, a $0.6 \%$ $(0.4 \%$ to $0.9 \%)$ reduction. The pattern of effect by both age and third of income is the same as that seen with a $20 \%$ tax, and the estimated revenue generated is $£ 139 \mathrm{~m}$ ( $£ 137 \mathrm{~m}$ to $£ 140 \mathrm{~m})$.

\section{Discussion}

A $20 \%$ sales tax on sugar sweetened drinks is predicted to reduce the number of adults in the UK who are obese by $180000(1.3 \%)$ and the number who are overweight by $285000(0.9 \%)$. The tax would predominantly affect people aged under 30 years, who are the major consumers of sugar sweetened drinks. The effect on obesity is estimated to be similar for each constituent country in the UK, and the predicted revenue generated is $£ 276 \mathrm{~m}$ ( $€ 326 \mathrm{~m} ; \$ 442$ ). We did not find greater health gains for poorer groups.

\section{Strengths and weaknesses of study}

The strengths of this study are the use of contemporary UK specific data, consideration of substitution to other drinks, and estimation of differential effects by income. We modelled the effect by income considering the main potential drivers of differences between income groups (price responsiveness, baseline consumption of sugar sweetened drinks, and prevalence of obesity). ${ }^{46}$ Unlike some studies,${ }^{22}{ }^{47}$ our measure of drinks consumption includes all drinks consumed, both at home and away from the home. The model also uses a validated set of equations that estimate the change in steady state body weight.

To carry out the modelling, we had to use data from a range of different sources as no single dataset contains all the relevant information. Although all datasets are reported to be representative of the UK population, this may not be the case and applying results from one dataset to another requires the assumption that the samples in each dataset were drawn from the same population. Noticeably, some small differences exist in the definitions used to define the different drinks categories. A fully linked dataset would also have given us more flexibility in the analysis, allowing us, for example, to estimate price response by different consumption, calorie, and body mass index groups.

Discussion is taking place in the economic community about the most appropriate way to estimate elasticity values and to model the effect of tax rises on consumption. The strength of our approach is the use of unconditional elasticity values that make allowance for people shifting expenditure between food and drink items. However, when estimating demand functions, identifying whether the causes of price variation are demand driven (for example, greater demand for sugar sweetened drinks in the summer might prompt retailers to raise prices) or supply driven (and so independent of demand; for example, change in production costs leading to a rise in sale price) is difficult. The former may lead to errors in the estimation of the true effect. ${ }^{46}$ If so, this could lead to a smaller effect of the tax than our estimates imply. We discuss below how our elasticity estimates compare with the literature, including studies using different techniques.

We were not able to model different price effects by age because the Living Costs and Food Survey does not contain individual information on purchasing, only household information; we therefore assumed identical price elasticities for all age groups. Applying these price elasticities to different age specific baseline consumption patterns may be inappropriate-notably, the youngest age group are high consumers of sugar sweetened drinks. Some evidence suggests that high consumers are less price sensitive than low consumers, ${ }^{46}$ which might suggest that the response in this age group would be less than we have estimated. Similarly, using the population average values for older people, whose consumption of sugar sweetened drinks is very low, suggests that older people increase their consumption of milk to such an extent that they may experience a small net increase in energy intake. This seems unlikely given that the older population consume relatively few sugar sweetened drinks, which might suggest a relatively limited response to the tax. Price responses may also differ (independently of consumption) among the different age groups. However, we are not aware of any empirical data on this. For these reasons, the absolute age group estimates should be treated with caution, but the relative effects, a much greater response in the young population, seem realistic. For the same reason as we were not able to calculate age specific price elasticities, we were unable to calculate price elasticities for different body mass index groups.

By using the National Diet and Nutrition Survey, we have been able to include the consumption of all soft drinks in our analyses, including that of drinks purchased for consumption away from the home. Nevertheless, our estimates of sugar sweetened drink consumption seem to underestimate consumption in comparison with sales data. The British Soft Drinks Association (a trade body) reported total sales of $163 \mathrm{~L} /$ person/year (assuming a 1:4 ratio for concentrates) of sugar sweetened drinks (that is, carbonates, concentrates, still and juice beverages, and energy drinks, but excluding water and diet beverages) in the UK in $2011{ }^{48}$ This is equivalent to $446 \mathrm{~mL} /$ person/day (around 670 $\mathrm{kJ} /$ person/day and $7 \%$ of recommended caloric intake). This can be compared with our estimate from the National Diet and Nutrition Survey of $123 \mathrm{~mL} /$ person/day (206 kJ/person/day). Similar differences between dietary surveys and sales data are also described for alcohol in the UK. ${ }^{49}$ If the manufacturers' figures reflect actual consumption, our estimates may underestimate the effect on obesity. These differences also account for the discrepancy between our estimate of revenue and that of $£ 1$ bn from the recent Sustain report, which was based on retail data. ${ }^{4}$

We have not explicitly considered substitution of drinks with food items. Other authors have suggested that price rises of sugar sweetened drinks are not associated with significant substitution to food. ${ }^{46}$ The tax modelled was a sales tax, as this was more practical to model than the excise tax preferred by health bodies. An excise tax results in a uniform price increase per unit volume, removing any incentive to switch to large portion sizes that will tend to represent "better value", under a sales tax. ${ }^{4}$

We have assumed that any tax rise is passed on fully to the consumer, but the actual pass-on rate could be less, or more, than $100 \%$. Recent data concerning the French tax on sugar sweetened drinks (and artificially sweetened drinks) suggests that a pass-on rate approaching $100 \%$ may be reasonable. ${ }^{50}$ Furthermore, we have considered only obesity as an outcome. The effects on other health outcomes, such as type 2 diabetes, dental caries, and cardiovascular disease, as well as the secondary effects of obesity, such as cancer or arthritis, have not been modelled.

When modelling the effect on obesity of the population, we have assumed that the prevalence of obesity for England, Wales, and Northern Ireland is the same as that measured by the Health Survey for England. The prevalence of obesity may be different in both Wales and Northern Ireland. Furthermore, when we 
estimated the baseline prevalence of obesity and distribution by both age group and third of income from the Health Survey for England and the Scottish Health Survey, the small numbers of respondents at this degree of disaggregation mean that reported results will be less accurate than overall population level results.

The credible intervals presented reflect the uncertainty surrounding the price elasticity estimates and not the uncertainty regarding the parameters in the relation between energy intake and obesity or uncertainty in estimates of sugar sweetened drink consumption. The uncertainty around price elasticity estimates is considerably greater than the parametric uncertainty surrounding the obesity modelling and is therefore preferentially reported. Structural uncertainties in the design of the model are also not reflected in our uncertainty estimates. Finally, the model is cross sectional and does not model how prevalence of obesity would shift over time as a result of the taxation. Modelling that does include a time component suggests that most of the effect from a tax would occur within two years, but the full effect may take up to five to 10 years to be seen. ${ }^{18}$

\section{Comparison with other studies}

One other study has modelled the effects of a $10 \%$ and a $20 \%$ price rise on sugar sweetened drink consumption in the UK. ${ }^{19}$ Our study explicitly set out to model the health effects of such a tax and included a full economic model to describe both the own price and cross price effects resulting from the tax. In terms of effect on consumption, $\mathrm{Ng}$ et al estimated a reduction in sugar sweetened drink intake of $104 \mathrm{~mL}(10 \%)$ per person per week compared with our predicted reduction of around $15 \% .{ }^{19}$ The substitution effects predicted in $\mathrm{Ng}$ et al's study are very slight, and as a result the predicted change in energy intake is larger (net decrease of $24 \mathrm{~kJ} /$ person/day compared with our estimate of $17 \mathrm{~kJ} /$ person/day).

A recent meta-analysis, largely based on US modelling studies, suggested that for every $1 \%$ increase in price, energy intake would reduce by $0.02 \% .^{51}$ This suggests an average reduction in energy intake of 33 (17 to 67) kJ/person/day. Our estimate is about half of this at just $17 \mathrm{~kJ}$. This is partly because the meta-analysis predominantly included studies with a high baseline consumption of sugar sweetened drinks, in which a tax may have greater potential to reduce energy intake. The lower levels of baseline sugar sweetened drink consumption in the UK compared with the US may in part explain why the effect on obesity that we estimate in the UK is much less than that estimated in the US. ${ }^{12}$ The differences with respect to other modelling studies may also be partly explained by their use of higher own price elasticity values for sugar sweetened drinks than we have calculated and used here. ${ }^{1822}{ }^{52}$ We cannot make direct comparisons between the results of our study and the results of recent studies of the effect of reducing sugar sweetened drink consumption on body weight in children, ${ }^{57}$ as the relation between energy balance and change in body mass index in children who are growing is different from that in adults.

In terms of own price elasticity values, a recent meta-analysis estimated an average own price effect for carbonated sugar sweetened drinks (a near equivalent of the category non-concentrated sugar sweetened drinks, which predominantly includes carbonated drinks) of -0.93 , larger than our value of $-0.81 .{ }^{51}$ Our estimated value is also at the lower end of the range of own price elasticities frequently cited for sugar sweetened drinks of -0.8 to -1.0 , based on one large review. ${ }^{52}$ Our own price estimate is comparable to experimental data (a $25 \%$ reduction for a $35 \%$ price rise) in a canteen study. ${ }^{53}$ However, all these estimates may be influenced by US studies in which higher estimates may reflect higher levels of consumption.

In terms of substitution effects, the major difference between our estimates and those from the US is that our data indicate that diet soft drinks are a substitute for sugar sweetened drinks, whereas US data suggest that diet soft drinks are a complement (as the price of sugar sweetened drinks goes up, consumption of diet drinks goes down). ${ }^{18} 22$ This may explain why a US tax on sugar sweetened drinks has been so heavily resisted, as a "double whammy" on sales of both diet soft drinks and sugar sweetened drinks would occur. ${ }^{18}$. Furthermore, our data suggest a switch to a variety of other drinks, whereas in the US the dominant pattern may be a switch towards fruit juice. ${ }^{182}$

Our estimates of the own price effect by income for non-concentrated sugar sweetened drinks suggest a smaller response by the lowest income group in comparison with the other two income groups, although the magnitude of the difference is small. This finding may run counter to what many people expect. Economic theory suggests that the response to a price change has two components-share of expenditure and a behavioural response. Although sugar sweetened drinks occupy a lower proportion of total expenditure as income rises, the Living Costs and Food Survey data suggests that they occupy a greater proportion of food and drink expenditure $(1.7 \%, 1.9 \%$, and $2.2 \%$ for income thirds 1,2 , and 3 respectively). This may go part way to explain the observed price elasticities. Secondly, the behavioural component may also vary with income. For example, a significant preference for sugar sweetened drinks among people on a lower income compared with those on a high income might suggest a relatively attenuated price response.

The literature suggests mixed findings with respect to price sensitivity of sugar sweetened drinks and income. Lin et al estimate a similar effect to ours, with a smaller response of -0.95 for the lowest income group compared with -1.3 in the highest income group. ${ }^{18}$ Conversely, another recent paper, also from the US, found greater price responsiveness among people on a lower income. ${ }^{46} \mathrm{~A}$ recent systematic review found greater responses by low income groups, but this was for a mixed group of confectionary and sugar sweetened drinks. ${ }^{54}$

\section{Meaning of study}

The principal group expected to benefit from a tax on sugar sweetened drinks would be people under the age of 30 years, because they have a higher consumption of such drinks. This is important to communicate to both the public and policy makers, who see the tax as a blanket measure on obesity. It would also suggest that an evaluation, particularly concerning health effects, should focus on younger people. Although improving the health of younger people has the potential to offer lifelong health gains, the complications of obesity typically present in later life, so savings to the health service are unlikely to be realised in the shorter term.

The main substitutes for sugar sweetened drinks seem to be diet drinks, milk, tea and coffee, and fruit juice. In terms of obesity, the shift to diet beverages will reduce calorie intake. However, other authors have voiced concerns about consumption of artificial sweeteners, because they may promote an appetite for sweet things, they harm bone and dental health, and their long term safety profile is not precisely clear. ${ }^{55}$ However, the European Food Safety Agency recently concluded that aspartame, the most common artificial sweetener, is safe at present consumption levels. ${ }^{56}$ The shift to milk consumption as sugar sweetened drink consumption falls might be expected. The rise in sugar sweetened drink consumption has been noted 
to have displaced milk from the diet, and this may partly account for the apparent detrimental effects of regular sugar sweetened drink consumption on bone health. ${ }^{57}$

We had hypothesised progressive health gains, but our results do not support this pattern. Although the highest income group experience the greatest reduction in obesity, the credible intervals between all three income groups overlap. We also note that many of the underlying determinants of potential differences (consumption levels, price elasticity, and prevalence of obesity) seem to be relatively uniform across income groups. Taken together in the UK context, this may suggest that the effect will be relatively uniform between the different groups, but this area warrants further exploration. Other studies, in the US setting, have found evidence of progressive health gains, ${ }^{47} 58$ and these income group differences seem to be partly driven by differences in consumption levels between income groups. ${ }^{58}$

We also note a trend for greater increases in weekly expenditure on drinks as income decreases. Given that a regressive tax is one in which the proportion of income spent falls as income rises, this supports the notion that the tax would be regressive in its financial effect. However, the average size of the financial effect is low at around 8p per person per week.

The predicted revenue generated following a $20 \%$ tax on sugar sweetened drinks is $£ 276 \mathrm{~m}$. This could be used to increase NHS funding during a period of budget restrictions or to subsidise foods with health benefits, such as fruit and vegetables. The Global Burden of Disease Study 2010 predicted that sugar sweetened drink consumption contributes a relatively small amount to UK population morbidity (28 000 disability adjusted life years) compared with low fruit and vegetable consumption (1 130000 disability adjusted life years) ${ }^{59}$ Using revenue from a sugar sweetened drink tax to reduce the prices of fruit and vegetables is a potential mechanism for further improving population health. ${ }^{60}$

The effect of this tax on consumption of sugar sweetened drinks is relatively large, around a $15 \%$ reduction. By comparison, the effects on obesity are relatively modest. This is in part because sugar sweetened drinks are not consumed in large amounts by the older adult population in whom obesity is more prevalent and causes more disease. Our study also shows that although such a tax would not be a panacea for obesity, it could make a useful contribution to a multi-pronged strategy to combat obesity and other diet related disease. ${ }^{3}$

\section{Unanswered questions}

The quantity of sugar sweetened drinks consumed in the UK remains uncertain. Whereas estimates from the National Diet and Nutrition Survey and Living Costs and Food Survey are broadly comparable (123 mL/adult/day versus 168 $\mathrm{mL} /$ person/day), the British Soft Drinks Association's figures are threefold to fourfold higher. ${ }^{48}{ }^{61}$ The level and pattern of consumption will determine the magnitude of the public health effects of a sugar sweetened drinks tax, as well as its effect on health inequalities. Further work should be done to clarify the level (and patterns) of sugar sweetened drink consumption in the UK.

This study has considered only the direct effects of the price rise itself. Secondary reductions in consumption may occur from the negative publicity surrounding sugar sweetened drinks, resulting from either the continuing debate about legislation or the stigma attached to public awareness of a special tax on health grounds. Interaction with individual level approaches (such as a dietitian's advice) to reduce sugar sweetened drink consumption may also occur.
The response of industry to the tax is uncertain, both the extent to which companies would pass the tax onto consumers and whether they would respond in other ways, either fighting the measure or promoting diet drinks as an alternative. This work has not considered public opinion, which may be critical when deciding whether a tax is adopted.

\section{Conclusion}

A $20 \%$ tax on sugar sweetened drinks is predicted to reduce the prevalence of obesity in the UK by $1.3 \%$ (around 180000 people). The greatest effects are seen for young people, and no significant differences are found between income groups. Both effects warrant further exploration. Taxation represents a measure to target population obesity, particularly among young people, but should not be seen as a panacea.

Contributors: $A D M B$ and OTM contributed equally to this manuscript. ADMB, OTM, MR, and PS devised the study. AK and RT provided advice on and undertook the econometric modelling. PS developed the PRIME model and provided specific guidance on modelling. ADMB and OTM did the health modelling and drafted the manuscript. All authors contributed to the study design and reviewed and critiqued the final manuscript. ADMB and OTM are the guarantors.

Funding: No explicit funding for this work was sought. MR and PS are funded by the British Heart Foundation. ADMB and OTM are National Institute for Health Research funded academic clinical fellows in public health.

Competing interests: All authors have completed the ICMJE uniform disclosure form at www.icmje.org/coi_disclosure.pdf (available from the corresponding author) and declare: no support from any organisation for the submitted work; RT and AK have received research grants from the Union of European Soft Drinks Association; MR and PS have received research grants from the British Heart Foundation; MR is chair of Sustain.

Ethical approval: This study used routinely collected publicly available datasets. As such, ethics approval was not required.

Data sharing: No additional data available.

Declaration of transparency: The lead authors (the manuscript's guarantors) affirm that the manuscript is an honest, accurate, and transparent account of the study being reported; that no important aspects of the study have been omitted; and that any discrepancies from the study as planned (and, if relevant, registered) have been explained.

1 Measuring up: the medical profession's prescription for the nation's obesity crisis. Academy of Medical Royal Colleges, 2013 (avaialble at www.aomrc.org.uk/publications/statements/ doc_view/9673-measuring-up.html).

2 Wojcicki JM. Healthy hospital food initiatives in the United States: time to ban sugar sweetened beverages to reduce childhood obesity. Acta Paediatr 2013;102:560-1.

Pomeranz JL. Advanced policy options to regulate sugar-sweetened beverages to support public health. J Public Health Policy 2012;33:75-88.

4 Sustain. A children's future fund: how food duties could provide the money to protect children's health and the world they grow up in. 2013. www.sustainweb.org/publications/ ?id=263.

5 Ebbeling CB, Feldman HA, Chomitz VR, Antonelli TA, Gortmaker SL, Osganian SK, et al. A randomized trial of sugar-sweetened beverages and adolescent body weight. N Engl J Med 2012;367:1407-16.

6 Malik VS, Popkin BM, Bray GA, Despres JP, Willett WC, Hu FB. Sugar-sweetened beverages and risk of metabolic syndrome and type 2 diabetes: a meta-analysis. Diabetes Care 2010;33:2477-83.

7 De Ruyter JC, Olthof MR, Seidell JC, Katan MB. A trial of sugar-free or sugar-sweetened beverages and body weight in children. N Engl J Med 2012;367:1397-406.

8 Malik VS, Schulze MB, Hu FB. Intake of sugar-sweetened beverages and weight gain: a systematic review. Am J Clin Nutr 2006;84:274-88.

9 Armfield JM, Spencer AJ, Roberts-Thomson KF, Plastow K. Water fluoridation and the association of sugar-sweetened beverage consumption and dental caries in Australian children. Am J Public Health 2013;103:494-500.

10 Malik VS, Popkin BM, Bray GA, Despres JP, Hu FB. Sugar-sweetened beverages, obesity, type 2 diabetes mellitus, and cardiovascular disease risk. Circulation 2010;121:1356-64.

11 Hu FB, Malik VS. Sugar-sweetened beverages and risk of obesity and type 2 diabetes: epidemiologic evidence. Physiol Behav 2010;100:47-54. 


\section{What is already known on this topic}

Regular consumption of sugar sweetened drinks increases the risk of obesity, diabetes, and dental caries

A tax on sugar sweetened drinks has been proposed as one means to reduce consumption and raise revenue; it is gaining traction both politically and among health advocacy organisations

Taxes on sugar sweetened beverages are likely to reduce consumption, but the effect on obesity in the UK and for different income groups is unknown

Progressive health gains (that is, the greatest health benefits for people on lower incomes) have been predicted

\section{What this study adds}

The number of people in the UK who are obese is predicted to reduce by $1.3 \%$ following the introduction of a tax on sugar sweetened drinks

Health gains may be similar for all income groups in the UK

The greatest reductions in obesity would occur among young people in the UK

12 Brownell KD, Farley T, Willett WC, Popkin BM, Chaloupka FJ, Thompson JW, et al. The public health and economic benefits of taxing sugar-sweetened beverages. N Engl J Med 2009;361:1599-605.

13 Mytton OT, Clarke D, Rayner M. Taxing unhealthy food and drinks to improve health BMJ 2012;344:e2931.

14 Tax sugary drinks to boost child health. The Guardian 2013 Jan 29

15 Bahl R. The uneasy case against discriminatory excise taxation: soft drink taxes in Ireland. Public Finance Review 2003;31(510).

16 Lentschner K. [Le marché des soft-drinks a la gueule de bois.] Le Figaro 2012 July 26.

17 Kim D, Kawachi I. Food taxation and pricing strategies to "thin out" the obesity epidemic. Am J Prev Med 2006;30:430-7.

18 Lin BH, Smith TA, Lee JY, Hall KD. Measuring weight outcomes for obesity intervention strategies: the case of a sugar-sweetened beverage tax. Econ Hum Biol 2011;9:329-41.

$19 \mathrm{Ng} \mathrm{SW}$, Ni Mhurchu C, Jebb SA, Popkin BM. Patterns and trends of beverage consumption among children and adults in Great Britain, 1986-2009. Br J Nutr 2012:108:536-51.

20 Duffey KJ, Gordon-Larsen P, Shikany JM, Guilkey D, Jacobs DR Jr, Popkin BM. Food price and diet and health outcomes: 20 years of the CARDIA Study. Arch Intern Med 2010;170:420-6.

21 Andreyeva T, Chaloupka FJ, Brownell KD. Estimating the potential of taxes on sugar-sweetened beverages to reduce consumption and generate revenue. Prev Med 2011;52:413-6.

22 Dharmasena S, Capps O Jr. Intended and unintended consequences of a proposed national tax on sugar-sweetened beverages to combat the U.S. obesity problem. Health Econ 2012;21:669-94

23 Department for the Environment Food and Rural Affairs. Living Costs and Food Survey 2010. DEFRA, 2011.

24 Department for Environment, Food and Rural Affairs. Expenditure on household and eating out food \& drink by income decile (equivalised income). 2010 (available from www. defra.gov.uk/statistics/foodfarm/food/familyfood/datasets/).

25 National Centre for Social Research. National Diet and Nutrition Survey. 2008-10. http:/ discover.ukdataservice.ac.uk/catalogue/?sn=6533\&type=Data\%20catalogue.

26 NatCen Social Research and Royal Free and University College Medical School. Department of Epidemiology and Public Health, Health Survey for England, 2010 [compute file]. 2nd ed. UK Data Archive [distributor], 2012. SN: 6986. http://dx.doi.org/10.5255/ UKDA-SN-6986-2.

27 ScotCen Social Research and University College London. Department of Epidemiology and Public Health, Scottish Health Survey, 2010 [computer file]. UK Data Archive [distributor], 2012. SN: 6987

28 Shiely F, Perry IJ, Lutomski J, Harrington J, Kelleher CC, McGee H, et al. Temporal trends in misclassification patterns of measured and self-report based body mass index categories-findings from three population surveys in Ireland. BMC Public Health 2010;10:560.

29 National Centre for Social Research, Welsh Health Survey, 2010 [computer file]. UK Data Archive [distributor], 2011. SN: 6895. http://dx.doi.org/10.5255/UKDA-SN-6895-1.

30 Health Survey Northern Ireland: first results from the 2010/11 survey. Department of Health, Social Services and Public Safety, 2011.

31 Office for National Statistics. Population estimates for England and Wales, mid 2011 (2011 Census based). 2012. www.ons.gov.uk/ons/publications/re-reference-tables.html? edition=tcm\%3A77-262039.

32 National Records of Scotland. 2011 Census day: usual resident population estimates by five-year age group and sex, Scotland. 2012. www.scotlandscensus.gov.uk/documents/ censusresults/release1a/rel1asbtablea1.xls.

33 Northern Ireland Neighbourhood Information Service. Census 2011 (Northern Ireland). www.ninis2.nisra.gov.uk/public/Home.aspx.

34 Deaton A, Muellbauer J. An almost ideal demand system. The American Economic Review 1980;70:312-26.

35 Blundell R, Meghir C. Bivariate alternatives to the Tobit model. J Econom 1987;34:179-200.

36 Tanner MA, Wong WH. The calculation of posterior distributions by data augmentation. J Am Stat Assoc 1987;82:528-40.

37 Edgerton DL. Weak separability and the estimation of elasticities in multistage demand systems. Am J Agric Econ 1997;79:62-79.

38 Scarborough P, Burg MR, Foster C, Swinburn B, Sacks G, Rayner M, et al. Increased energy intake entirely accounts for increase in body weight in women but not in men in the UK between 1986 and 2000. Br J Nutr 2011:105:1399-404.

39 Scarborough P, Morgan RD, Webster P, Rayner M. Differences in coronary heart disease, stroke and cancer mortality rates between England, Wales, Scotland and Northern Ireland: the role of diet and nutrition. BMJ Open 2011;1:e000263.

40 Nichols M, Scarborough P, Allender S, Rayner M. What is the optimal level of population alcohol consumption for chronic disease prevention in England? Modelling the impact of changes in average consumption levels. BMJ Open 2012;2:e000957.
41 Scarborough P, Allender S, Clarke D, Wickramasinghe K, Rayner M. Modelling the health impact of environmentally sustainable dietary scenarios in the UK. Eur J Clin Nutr 2012;66:710-5.

42 British Heart Foundation Health Promotion Research Group, Department of Public Health, University of Oxford. Coronary heart disease statistics-a compendium of statistics. British Heart Foundation, 2012 (available at www.bhf.org.uk/publications/view-publication.aspx? ps $=1002097)$.

43 Christiansen E, Garby L. Prediction of body weight changes caused by changes in energy balance. Eur J Clin Invest 2002;32:826-30.

44 Briggs A, Mytton O, Scarborough P, Rayner M. Appendix 8: Modelling the effects of a $10 \%$ sugar sweetened drinks tax on obesity and overweight in Ireland: a report to inform the Health Impact Assessment. In: Proposed sugar sweetened drinks tax: health impac assessment (HIA). Institute of Public Health in Ireland, 2012:116-53.

45 Hall K, Jordan P. Modelling weight-loss maintenance to help prevent body weight regain Am J Clin Nutr 2008:88:1495-503.

46 Finkelstein EA, Zhen C, Bilger M, Nonnemaker J, Farooqui AM, Todd JE. Implications of a sugar-sweetened beverage (SSB) tax when substitutions to non-beverage items are considered. $J$ Health Econ 2013;32:219-39.

47 Finkelstein EA, Zhen C, Nonnemaker J, Todd JE. Impact of targeted beverage taxes on higher- and lower-income households. Arch Intern Med 2010;170:2028-34

48 British Soft Drinks Association. Long term commitment for long term success: 2012. BDSA UK Soft Drinks Report. British Soft Drinks Association, 2012.

49 Meier PS, Meng Y, Holmes J, Baumberg B, Purshouse R, Hill-McManus D, et al. Adjusting for unrecorded consumption in survey and per capita sales data: quantification of impact on gender- and age-specific alcohol-attributable fractions for oral and pharyngeal cancers in Great Britain. Alcohol Alcohol 2013;48:241-9.

50 Berardi N, Sevestere P, Tepaut M, Vigneron A. The impact of a 'soda tax' on prices: evidence from French micro data. Banque de France, 2012

51 Eyles H, Ni Mhurchu C, Nghiem N, Blakely T. Food pricing strategies, population diets, and non-communicable disease: a systematic review of simulation studies. PLoS Med 2012;9:e1001353.

52 Andreyeva T, Long MW, Brownell KD. The impact of food prices on consumption: a systematic review of research on the price elasticity of demand for food. Am J Public Health 2010;100:216-22.

53 Block JP, Chandra A, McManus KD, Willett WC. Point-of-purchase price and education intervention to reduce consumption of sugary soft drinks. Am J Public Health 2010;100:1427-33

54 Green R, Cornelsen L, Dangour AD, Turner R, Shankar B, Mazzocchi M, et al. The effect of rising food prices on food consumption: systematic review with meta-regression. $B M J$ 2013;346:f3703.

55 Kosinska M. Open letter. 2011. www.epha.org/IMG/pdf/Open_Letter_to_the_French_ Government_EN.pdf.

56 EFSA Panel on Food Additives and Nutrient Sources added to Food. Draft scientific opinion on the re-evaluation of aspartame (E 951) as a food additive. European Food Safety Agency, 2013 (available at www.efsa.europa.eu/en/consultationsclosed/call/130108. pdf).

57 Vartanian LR, Schwartz MB, Brownell KD. Effects of soft drink consumption on nutrition and health: a systematic review and meta-analysis. Am J Public Health 2007;97:667-75.

58 Zhen C, Finkelstein E, Nonnemaker J, Karns SA, Todd JE. Predicting the effects of sugar-sweetened bevarge taxes on food and beverage demand in a large demand system. Am J Agric Econ 2013; published online 29 July.

59 Murray CJL, Richards MA, Newton JN, Fenton KA, Anderson HR, Atkinson C, et al. UK health performance: findings of the Global Burden of Disease Study 2010. Lancet 2013;381:997-1020.

60 Waterlander WE, de Boer MR, Schuit AJ, Seidell JC, Steenhuis IH. Price discount significantly enhance fruit and vegetable purchases when combined with nutrition education: a randomized controlled supermarket trial. Am J Clin Nutr 2013;97:886-95.

61 Department for Environment, Food and Rural Affairs. Family food datasets: UK household purchased quantities of food and drink, averages per person per week (2008). 2011 (available from www.gov.uk/government/statistical-data-sets/family-food-datasets).

\section{Accepted: 03 September 2013}

\section{Cite this as: BMJ 2013;347:f6189}

This is an Open Access article distributed in accordance with the Creative Commons Attribution Non Commercial (CC BY-NC 3.0) license, which permits others to distribute, remix, adapt, build upon this work non-commercially, and license their derivative works on different terms, provided the original work is properly cited and the use is non-commercial. See: http://creativecommons.org/licenses/by-nc/3.0/. 


\section{Tables}

Table 1 | Average daily consumption and energy intakes from different drinks by age

\begin{tabular}{|c|c|c|c|c|}
\hline \multirow[b]{2}{*}{ Drink group } & \multicolumn{4}{|c|}{ Daily consumption of drinks in $\mathrm{mL}$ (energy intake from drinks in $\mathrm{kJ}$ ) } \\
\hline & $16-29$ years & $30-49$ years & $\geq 50$ years & All adults* \\
\hline Sugar sweetened drinks (concentrated) & $154(231)$ & $58(88)$ & $28(43)$ & $59(102)$ \\
\hline Sugar sweetened drinks (non-concentrated) & $147(221)$ & $59(89)$ & $33(53)$ & $64(104)$ \\
\hline Milk & $131(280)$ & $151(314)$ & $184(387)$ & $162(338)$ \\
\hline Fruit juice & $56(86)$ & $60(93)$ & $49(75)$ & $54(84)$ \\
\hline Diet soft drinks (concentrated) & $82(6)$ & $43(3)$ & $12(1)$ & $33(3)$ \\
\hline Diet soft drinks (non-concentrated) & $78(6)$ & $68(5)$ & $28(2)$ & $54(4)$ \\
\hline Tea and coffee & $719(0)$ & $1130(0)$ & $1228(0)$ & $1107(0)$ \\
\hline Beer & $256(332)$ & $271(352)$ & $152(198)$ & $221(282)$ \\
\hline Wine & $24(67)$ & $67(188)$ & $67(187)$ & $60(160)$ \\
\hline Other alcohol & $13(70)$ & $5(26)$ & $5(26)$ & $7(36)$ \\
\hline Total & 1660 (1299) & $1912(1159)$ & $1786(973)$ & $1821(1112)$ \\
\hline
\end{tabular}

*Aged 16 years and over. 
Table 2| Average daily consumption and energy intakes from different drinks by thirds of income

\begin{tabular}{lccc} 
& \multicolumn{3}{c}{ Daily consumption of drinks in $\mathbf{~ L}$ (energy intake from beverages in kJ) } \\
\cline { 2 - 4 } Drink group & Third 1 (lowest income) & Third 2 & Third 3 (highest income) \\
Sugar sweetened drinks (concentrated) & $72(108)$ & $47(71)$ & $61(92)$ \\
\hline Sugar sweetened drinks (non-concentrated) & $79(119)$ & $52(78)$ & $68(102)$ \\
\hline Milk & $149(344)$ & $165(338)$ & $164(331)$ \\
\hline Fruit juice & $50(83)$ & $43(84)$ & $68(81)$ \\
\hline Diet soft drinks (concentrated) & $31(3)$ & $26(3)$ & $42(4)$ \\
\hline Diet soft drinks (non-concentrated) & $53(4)$ & $45(4)$ & $71(5)$ \\
\hline Tea and coffee & $959(0)$ & $1128(0)$ & $1232(0)$ \\
\hline Beer & $267(230)$ & $169(252)$ & $248(357)$ \\
\hline Wine & $22(140)$ & $52(162)$ & $99(170)$ \\
\hline Other alcohol & $6(28)$ & $5(24)$ & $12(57)$ \\
\hline Total & $1688(1052)$ & $1732(1072)$ & $2065(1212)$ \\
\hline
\end{tabular}




\begin{tabular}{|c|c|c|c|c|c|c|c|c|c|c|c|c|}
\hline Drink group & Milk & Water & $\begin{array}{l}\text { Fruit } \\
\text { juice }\end{array}$ & $\begin{array}{l}\text { Diet soft drinks } \\
\text { (concentrated) }\end{array}$ & $\begin{array}{c}\text { SSDs } \\
\text { (concentrated) }\end{array}$ & $\begin{array}{c}\text { Diet soft drinks } \\
\text { (non-concentrated) }\end{array}$ & $\begin{array}{c}\text { SSDs } \\
\text { (non-concentrated) }\end{array}$ & $\begin{array}{c}\text { Tea } \\
\text { and } \\
\text { coffee }\end{array}$ & $\begin{array}{l}\text { Other } \\
\text { drinks }\end{array}$ & Beer & Wine & $\begin{array}{l}\text { Other } \\
\text { alcohol }\end{array}$ \\
\hline Milk & $\begin{array}{l}-0.981^{*} \\
(0.039)\end{array}$ & $\begin{array}{c}0.002 \\
(0.001)\end{array}$ & $\begin{array}{l}0.008^{*} \\
(0.001)\end{array}$ & $0.012^{*}(0.001)$ & $0.032^{*}(0.004)$ & $0.070^{*}(0.008)$ & $0.157^{*}(0.017)$ & $\begin{array}{c}0.165^{\star} \\
(0.028) \\
\end{array}$ & $\begin{array}{l}0.017^{*} \\
(0.003)\end{array}$ & $\begin{array}{c}0.002 \\
(0.002)\end{array}$ & $\begin{array}{c}0.003 \\
(0.002)\end{array}$ & $\begin{array}{c}0.002 \\
(0.002) \\
\end{array}$ \\
\hline Water & $\begin{array}{c}0.016 \\
(0.014) \\
\end{array}$ & $\begin{array}{l}-1.174^{*} \\
(0.221)\end{array}$ & $\begin{array}{c}0.009 \\
(0.009)\end{array}$ & $0.008(0.006)$ & $0.021(0.015)$ & $0.051(0.032)$ & $0.098(0.072)$ & $\begin{array}{c}0.189 \\
(0.181) \\
\end{array}$ & $\begin{array}{c}0.019 \\
(0.019) \\
\end{array}$ & $\begin{array}{c}0.001 \\
(0.002)\end{array}$ & $\begin{array}{c}0.002 \\
(0.002)\end{array}$ & $\begin{array}{c}0.001 \\
(0.001) \\
\end{array}$ \\
\hline Fruit juice & $\begin{array}{l}0.025^{\star} \\
(0.005)\end{array}$ & $\begin{array}{c}0.003 \\
(0.003)\end{array}$ & $\begin{array}{l}-0.971^{*} \\
(0.060)\end{array}$ & $0.010^{*}(0.002)$ & $0.027^{\star}(0.005)$ & $0.058^{\star}(0.010)$ & $0.128^{*}(0.024)$ & $\begin{array}{l}0.121^{*} \\
(0.053)\end{array}$ & $\begin{array}{l}0.013^{*} \\
(0.006)\end{array}$ & $\begin{array}{c}0.001 \\
(0.001) \\
\end{array}$ & $\begin{array}{c}0.002 \\
(0.002) \\
\end{array}$ & $\begin{array}{c}0.001 \\
(0.001) \\
\end{array}$ \\
\hline $\begin{array}{l}\text { Diet soft drinks } \\
\text { (concentrated) }\end{array}$ & $\begin{array}{l}0.019^{\star} \\
(0.004)\end{array}$ & $\begin{array}{c}0.002 \\
(0.001) \\
\end{array}$ & $\begin{array}{l}0.005^{\star} \\
(0.001)\end{array}$ & $-0.979^{*}(0.220)$ & $0.304(0.171)$ & $0.082(0.141)$ & $0.073(0.129)$ & $\begin{array}{l}0.110^{*} \\
(0.025)\end{array}$ & $\begin{array}{l}0.011^{*} \\
(0.003)\end{array}$ & $\begin{array}{c}0.001 \\
(0.002)\end{array}$ & $\begin{array}{c}0.002 \\
(0.002) \\
\end{array}$ & $\begin{array}{c}0.001 \\
(0.001) \\
\end{array}$ \\
\hline $\begin{array}{l}\text { SSDs } \\
\text { (concentrated) }\end{array}$ & $\begin{array}{l}0.020^{*} \\
(0.003)\end{array}$ & $\begin{array}{c}0.002 \\
(0.001) \\
\end{array}$ & $\begin{array}{l}0.005^{\star} \\
(0.001)\end{array}$ & $0.107(0.066)$ & $-0.921^{*}(0.077)$ & $0.100^{*}(0.050)$ & $0.179^{*}(0.048)$ & $\begin{array}{l}0.112^{*} \\
(0.020)\end{array}$ & $\begin{array}{l}0.012^{*} \\
(0.002)\end{array}$ & $\begin{array}{c}0.001 \\
(0.002)\end{array}$ & $\begin{array}{c}0.002 \\
(0.002) \\
\end{array}$ & $\begin{array}{c}0.001 \\
(0.001) \\
\end{array}$ \\
\hline $\begin{array}{l}\text { Diet soft drinks } \\
\text { (non-concentrated) }\end{array}$ & $\begin{array}{l}0.026^{*} \\
(0.003)\end{array}$ & $\begin{array}{l}0.002^{*} \\
(0.001)\end{array}$ & $\begin{array}{l}0.007^{\star} \\
(0.001)\end{array}$ & $0.005(0.026)$ & $0.027(0.025)$ & $-0.903^{\star}(0.031)$ & $0.167^{\star}(0.028)$ & $\begin{array}{l}0.147^{*} \\
(0.024)\end{array}$ & $\begin{array}{l}0.015^{\star} \\
(0.003)\end{array}$ & $\begin{array}{c}0.002 \\
(0.002) \\
\end{array}$ & $\begin{array}{c}0.003 \\
(0.003) \\
\end{array}$ & $\begin{array}{c}0.002 \\
(0.002) \\
\end{array}$ \\
\hline $\begin{array}{l}\text { SSDs } \\
\text { (non-concentrated) }\end{array}$ & $\begin{array}{l}0.027^{\star} \\
(0.003)\end{array}$ & $\begin{array}{l}0.002^{*} \\
(0.001)\end{array}$ & $\begin{array}{l}0.008^{*} \\
(0.001)\end{array}$ & $-0.004(0.011)$ & $0.013(0.012)$ & $0.063^{*}(0.015)$ & $-0.811^{*}(0.024)$ & $\begin{array}{l}0.154^{*} \\
(0.025)\end{array}$ & $\begin{array}{l}0.016^{*} \\
(0.003)\end{array}$ & $\begin{array}{c}0.002 \\
(0.002) \\
\end{array}$ & $\begin{array}{c}0.003 \\
(0.003) \\
\end{array}$ & $\begin{array}{c}0.002 \\
(0.002) \\
\end{array}$ \\
\hline Tea and coffee & $\begin{array}{l}0.031^{*} \\
(0.005)\end{array}$ & $\begin{array}{c}0.005 \\
(0.003) \\
\end{array}$ & $\begin{array}{l}0.007^{\star} \\
(0.003)\end{array}$ & $0.013^{*}(0.002)$ & $0.035^{\star}(0.005)$ & $0.076^{*}(0.012)$ & $0.169^{*}(0.026)$ & $\begin{array}{l}-0.912^{*} \\
(0.084)\end{array}$ & $\begin{array}{l}-0.006 \\
(0.018) \\
\end{array}$ & $\begin{array}{c}0.002 \\
(0.002) \\
\end{array}$ & $\begin{array}{c}0.002 \\
(0.003) \\
\end{array}$ & $\begin{array}{c}0.002 \\
(0.002) \\
\end{array}$ \\
\hline Other drinks & $\begin{array}{l}0.016^{*} \\
(0.005)\end{array}$ & $\begin{array}{c}0.003 \\
(0.002)\end{array}$ & $\begin{array}{l}0.004^{*} \\
(0.002)\end{array}$ & $0.007^{\star}(0.002)$ & $0.018^{*}(0.006)$ & $0.038^{\star}(0.013)$ & $0.089^{*}(0.028)$ & $\begin{array}{c}0.340 \\
(0.186) \\
\end{array}$ & $\begin{array}{l}-0.822^{*} \\
(0.155)\end{array}$ & $\begin{array}{c}0.001 \\
(0.001) \\
\end{array}$ & $\begin{array}{c}0.001 \\
(0.002)\end{array}$ & $\begin{array}{c}0.001 \\
(0.001) \\
\end{array}$ \\
\hline Beer & $\begin{array}{l}-0.001 \\
(0.001)\end{array}$ & $\begin{array}{c}0.000 \\
(0.000)\end{array}$ & $\begin{array}{c}0.000 \\
(0.000) \\
\end{array}$ & $-0.001(0.001)$ & $-0.001(0.001)$ & $-0.004(0.003)$ & $-0.006(0.006)$ & $\begin{array}{l}-0.007 \\
(0.006) \\
\end{array}$ & $\begin{array}{l}-0.001 \\
(0.001) \\
\end{array}$ & $\begin{array}{l}-0.921^{*} \\
(0.088)\end{array}$ & $\begin{array}{l}0.032^{*} \\
(0.005)\end{array}$ & $\begin{array}{l}0.016^{*} \\
(0.005) \\
\end{array}$ \\
\hline Wine & $\begin{array}{l}-0.001 \\
(0.001)\end{array}$ & $\begin{array}{c}0.000 \\
(0.000)\end{array}$ & $\begin{array}{l}-0.001 \\
(0.000)\end{array}$ & $-0.001(0.001)$ & $-0.002(0.002)$ & $-0.005(0.003)$ & $-0.008(0.007)$ & $\begin{array}{l}-0.008 \\
(0.007)\end{array}$ & $\begin{array}{l}-0.001 \\
(0.001) \\
\end{array}$ & $\begin{array}{l}0.022^{*} \\
(0.003) \\
\end{array}$ & $\begin{array}{c}-1.009^{*} \\
(0.037)\end{array}$ & $\begin{array}{l}0.021^{*} \\
(0.003) \\
\end{array}$ \\
\hline Other alcohol & $\begin{array}{l}-0.001 \\
(0.001)\end{array}$ & $\begin{array}{c}0.000 \\
(0.000)\end{array}$ & $\begin{array}{c}0.000 \\
(0.000)\end{array}$ & $-0.001(0.001)$ & $-0.001(0.001)$ & $-0.003(0.003)$ & $-0.006(0.007)$ & $\begin{array}{l}-0.006 \\
(0.006)\end{array}$ & $\begin{array}{l}-0.001 \\
(0.001)\end{array}$ & $\begin{array}{l}0.018^{*} \\
(0.006)\end{array}$ & $\begin{array}{l}0.035^{\star} \\
(0.006)\end{array}$ & $\begin{array}{c}-0.969^{*} \\
(0.110)\end{array}$ \\
\hline
\end{tabular}

SSD=sugar sweetened drink.

Elasticity estimates refer to price rise for item listed in top row with respect to quantity change for those listed in first column.

*Elasticity estimates with $95 \%$ confidence intervals that exclude zero. 
Table 4 | Change in consumption of drinks as result of $\mathbf{2 0} \%$ tax. Values are percentages

\begin{tabular}{lcccc} 
& \multicolumn{5}{c}{ Thirds of income } \\
\cline { 2 - 5 } Drink group & $\mathbf{1}$ (lowest) & $\mathbf{2}$ & $\mathbf{3}$ (highest) & All \\
Sugar sweetened drinks (concentrated) & -15.9 & -13.7 & -15.0 & -14.8 \\
\hline Sugar sweetened drinks (non-concentrated) & -15.2 & -15.9 & -16.8 & -16.0 \\
\hline Milk & 4.3 & 3.9 & 3.2 & 3.7 \\
\hline Fruit juice & 3.5 & 2.6 & 3.3 & 3.1 \\
\hline Diet soft drinks (concentrated) & 11.8 & 4.7 & 6.4 & 7.5 \\
\hline Diet soft drinks (non-concentrated) & 5.4 & 3.4 & 2.9 & 3.9 \\
\hline Tea and coffee & 4.1 & 4.8 & 3.2 & 4.1 \\
\hline Other drinks & 2.8 & 2.0 & 1.6 & 2.1 \\
\hline Beer & 0 & 0 & -0.4 & -0.1 \\
\hline Wine & 0 & 0 & -0.6 & -0.2 \\
\hline Other alcohol & 0 & 0 & -0.4 & -0.1 \\
\hline Water & 1.1 & 2.1 & 3.9 & 2.4 \\
\hline
\end{tabular}


Table 5| Daily change in energy intake per person by age and third of income following $\mathbf{2 0} \%$ sugar sweetened drinks tax. Values are $\mathbf{k J}$ (95\% credible interval)

\begin{tabular}{lcccc} 
& \multicolumn{4}{c}{ Age group (years) } \\
\cline { 2 - 5 } Third of income & $\mathbf{1 6 - 2 9}$ & $\mathbf{3 0 - 4 9}$ & $\geq 50$ & Overall \\
\cline { 2 - 5 } 1 (lowest) & $-55.8(-71.3$ to -39.2$)$ & $-13.6(-22.5$ to -3.3$)$ & $-0.7(-8.2$ to 8.7$)$ & $-19.2(-29.3$ to -7.6$)$ \\
\hline 2 & $-54.2(-67.8$ to -39.9$)$ & $-12.3(-19.3$ to -4.9$)$ & $6.3(0.7$ to 12.7$)$ & $-13.4(-21.2$ to -4.8$)$ \\
\hline 3 (highest) & $-69.6(-84.3$ to -55.2$)$ & $-18.2(-25.2$ to -11.2$)$ & $-4.6(-10.5$ to 1.6$)$ & $-23.2(-31.3$ to -15.0$)$ \\
\hline Overall & $-56.3(-64.4$ to -47.9$)$ & $-13.0(-17.5$ to -8.2$)$ & $1.7(-2.2$ to 5.9$)$ & $-16.7(-21.7$ to -11.3$)$ \\
\hline
\end{tabular}

Overall results adjusted for variation in baseline consumption by age (16-29, 30-49, and $\geq 50$ years). 
Table $6 \mid$ Change in obese (BMI $\geq 30$ ) and overweight (BMI $\geq 25$ ) population for constituent countries in UK following implementation of $20 \%$ tax on sugar sweetened drinks

\begin{tabular}{|c|c|c|c|c|}
\hline \multirow[b]{2}{*}{ Country } & \multicolumn{2}{|c|}{ Change in $\mathrm{No}(95 \% \mathrm{Cl})$ of people obese or overweight } & \multicolumn{2}{|c|}{$\begin{array}{l}\text { Change in percentage }(95 \% \mathrm{Cl}) \text { of obese or overweight } \\
\text { population }\end{array}$} \\
\hline & $\mathrm{BMI} \geq 30$ & $\mathrm{BMI} \geq 25$ & $\mathrm{BMI} \geq 30$ & $B M I \geq 25$ \\
\hline England & $-151500(-297400$ to -92300$)$ & $-240600(-307500$ to -170300$)$ & $-1.3(-1.7$ to -0.8$)$ & $-0.9(-1.1$ to -0.6$)$ \\
\hline Wales & $-8300(-11500$ to -4800$)$ & $-13300(-17100$ to -9300$)$ & $-1.2(-1.6$ to -0.7$)$ & $-0.8(-1.0$ to -0.6$)$ \\
\hline Scotland & $-15200(-21100$ to -9100$)$ & $-12200(-28700$ to -15400$)$ & $-1.2(-1.7$ to -0.7$)$ & $-0.8(-1.0$ to -0.5$)$ \\
\hline Northern Ireland & $-5300(-7200$ to -2200$)$ & $-8500(-10800$ to -6100$)$ & $-1.4(-1.8$ to -0.9$)$ & $-0.9(-1.2$ to -0.7$)$ \\
\hline UK & $-180400(-247100$ to -109500$)$ & $-284600(-364100$ to -201000$)$ & $-1.3(-1.7$ to -0.8$)$ & $-0.9(-1.1$ to -0.6$)$ \\
\hline
\end{tabular}

$\mathrm{BMI}=$ body mass index; $\mathrm{Cl}=$ credible interval.

Results adjusted for age (16-29, 30-49, and $\geq 50$ years). 
Table $7 \mid$ Change in obese (BMI $\geq 30$ ) and overweight (BMI $\geq 25)$ population by age and thirds of income

\begin{tabular}{|c|c|c|c|c|}
\hline & \multicolumn{2}{|c|}{ Change in $\mathrm{No}(95 \% \mathrm{Cl})$ of people obese or overweight } & \multicolumn{2}{|c|}{$\begin{array}{l}\text { Change in percentage }(95 \% \mathrm{Cl}) \text { of obese or overweight } \\
\text { population }\end{array}$} \\
\hline & $\mathrm{BMI} \geq 30$ & $B M I \geq 25$ & $\mathrm{BMI} \geq 30$ & $B M I \geq 25$ \\
\hline \multicolumn{5}{|c|}{ By income group } \\
\hline Income third 1 & $-58900(-96000$ to -15600$)$ & $-87500(-129900$ to -39400$)$ & $-1.3(-2.0$ to -0.3$)$ & $-0.9(-1.3$ to -0.4$)$ \\
\hline Income third 2 & $-47700(-84300$ to -7400$)$ & $-82300(-124800$ to -36300$)$ & $-0.9(-1.6$ to -0.1$)$ & $-0.7(-1.0$ to -0.3$)$ \\
\hline Income third 3 & $-97300(-134900$ to -58600$)$ & $-145300(-193900$ to -96000$)$ & $-2.1(-2.9$ to -1.3$)$ & $-1.2(-1.6$ to -0.8$)$ \\
\hline \multicolumn{5}{|l|}{ By age group } \\
\hline $16-29$ years & $-127800(-145800$ to -109000$)$ & $-227200(-260000$ to -193200$)$ & $-7.6(-8.6$ to -6.4$)$ & $-4.2(-4.8$ to -3.6$)$ \\
\hline $30-49$ years & $-64100(-86200$ to -40800$)$ & $-67500(-90900$ to -42800$)$ & $-1.3(-1.7$ to -0.8$)$ & $-0.6(-0.8$ to -0.4$)$ \\
\hline$\geq 50$ years & $11500(-15100$ to 40300$)$ & $10000(-13200$ to 35000$)$ & $0.2(-0.2$ to 0.5$)$ & $0.1(-0.1$ to 0.2$)$ \\
\hline
\end{tabular}

$\mathrm{BMI}=$ body mass index; $\mathrm{Cl}=$ credible interval. 
Table 8/ Change in mean body mass index ( $95 \%$ credible interval) by age and income

\begin{tabular}{lcccc} 
& \multicolumn{4}{c}{ Age group (years) } \\
\cline { 2 - 5 } Third of income & $\mathbf{1 6 - 2 9}$ & $\mathbf{3 0 - 4 9}$ & $\geq 50$ & Overall \\
\hline (lowest) & $-0.24(-0.30$ to -0.17$)$ & $-0.06(-0.10$ to -0.01$)$ & $0(-0.04$ to 0.04$)$ & $-0.08(-0.13$ to -0.03$)$ \\
\hline 2 & $-0.22(-0.28$ to -0.17$)$ & $-0.05(-0.08$ to -0.02$)$ & $0.03(0$ to 0.07$)$ & $-0.06(-0.09$ to -0.02$)$ \\
\hline 3 (highest) & $-0.28(-0.34$ to -0.22$)$ & $-0.08(-0.10$ to -0.05$)$ & $-0.02(-0.05$ to 0.01$)$ & $-0.10(-0.13$ to -0.06$)$ \\
\hline Overall & $-0.23(-0.28$ to -0.20$)$ & $-0.05(-0.07$ to -0.03$)$ & $0.01(-0.01$ to 0.03$)$ & $-0.07(-0.09$ to -0.05$)$ \\
\hline
\end{tabular}




\section{Figures}

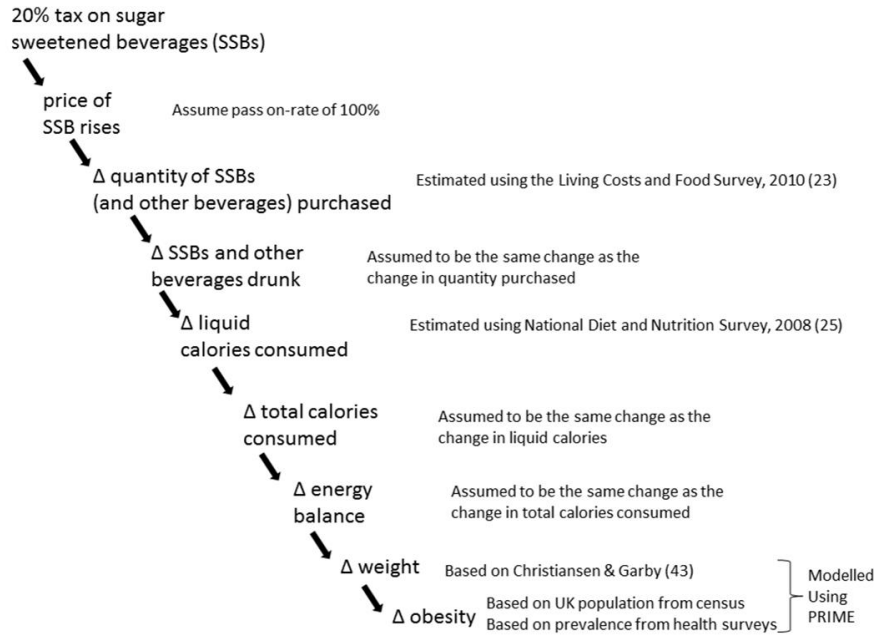

Fig 1 Modelled causal pathway between sugar sweetened drink taxation and obesity

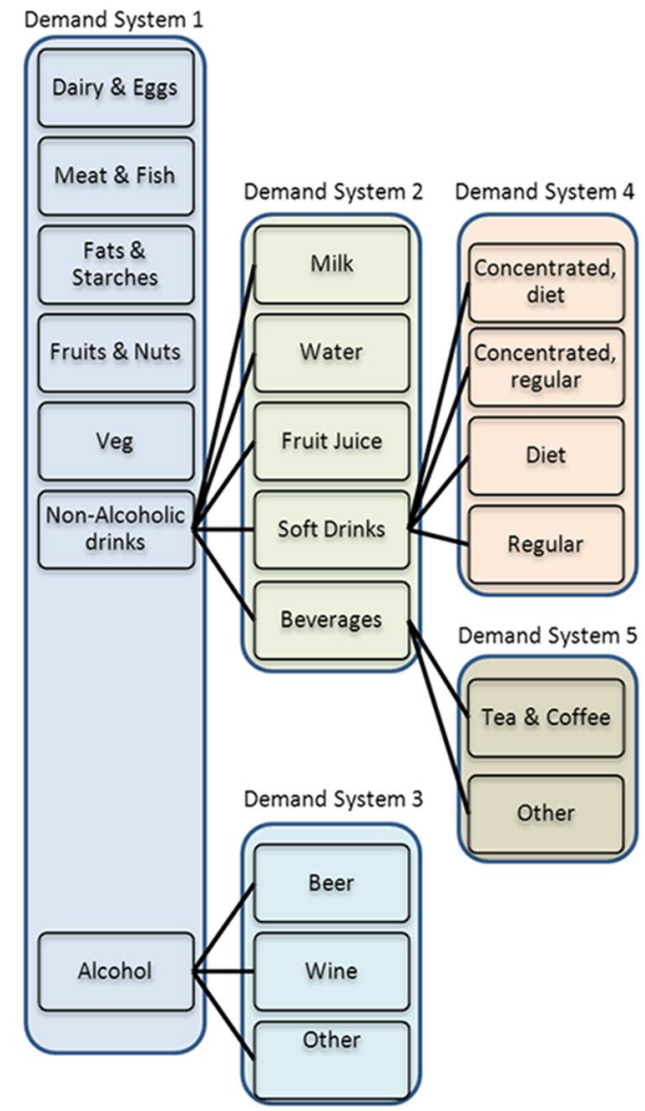

Fig 2 Categorisation of drinks and demand systems estimated 